\title{
Urgent need for novel antibiotics in Republic of Korea to combat multidrug-resistant bacteria
}

\author{
Hyo-Jin Lee ${ }^{1,2}$ and Dong-Gun Lee $e^{1,2,3}$
}

\begin{abstract}
${ }^{1}$ Division of Infectious Diseases, Department of Internal Medicine, ${ }^{2}$ Vaccine Bio Research Institute, College of Medicine, The Catholic University of Korea, Seoul; ${ }^{3}$ Catholic Hematology Hospital, The Catholic University of Korea, Seoul, Korea
\end{abstract}

Received : December 1, 2021

Accepted: January 21, 2022

\section{Correspondence to}

Dong-Gun Lee, M.D.

Division of Infectious Diseases, Department of Internal Medicine, Seoul St. Mary's Hospital, College of Medicine, The Catholic University of Korea, 222 Banpodaero, Seocho-gu, Seoul 06591, Korea

Tel: +82-2-2258-6003

Fax: +82-2-785-7944

E-mail: symonlee@catholic.ac.kr https://orcid.org/0000-0003-

4655-0641
Multidrug resistance in bacteria is an important issue and is increasing in frequency worldwide because of the limitations of therapeutic agents. From 2010 to 2019, 14 new systemic antibiotics received regulatory approval in the United States. However, few new antibiotics have been introduced in Republic of Korea to combat multidrug-resistant pathogens. Here, we introduce six novel antibiotics for Gram-positive bacteria and five for Gram-negative bacteria approved by the United States Food and Drug Administration and the European Medicines Agency from 2009 to October 2021, and recommend that they be approved for use in Republic of Korea at the earliest possible date.

Keywords: Anti-bacterial agents; Drug resistance, multiple; Methicillin-resistant Staphylococcus aureus; Carbapenem-resistant Enterobacteriaceae; Antimicrobial stewardship

\section{INTRODUCTION}

Multidrug-resistant (MDR) bacteria is a critical problem that is on the increase worldwide because of limitations in available therapeutic agents [1-3]. Consequently, the development of new antibiotics is a matter of urgency. From 2010 to 2019, 14 new systemic antibiotics received regulatory approval in the United States [4,5]. In Republic of Korea, MDR bacteria are prevalent not only in nosocomial infections but also in community-acquired infections [6-11]. The Korea Disease Control and Prevention Agency designated vancomycin-resistant Staphylococcus aureus (VRSA) and carbapenem-resistant Enterobacterales (CRE) as group 2 nationally notifiable infectious diseases, and methicillin-resistant $S$. aureus (MRSA), vancomycin-resistant Enterococcus (VRE), mul- tidrug-resistant Pseudomonas aeruginosa (MRPA), and multidrug-resistant Acinetobacter baumannii (MRAB) as group 4 nationally notifiable infectious diseases [12]. According to the Korean global antimicrobial resistance surveillance system, $53.2 \%$ of $S$. aureus blood strains in Republic of Korea were MRSA and 34\% of Enterococcus faecium strains were VRE in 2017 [13]. In 2015, 85\% of $A$. baumannii and $35 \%$ of $P$. aeruginosa were resistant to imipenem [12]. The prevalence of CRE infections has rapidly increased [14]. In Republic of Korea, the challenges associated with obtaining approval for new drugs complicates treatment of infections caused by MDR bacteria. These challenges include the high cost of new antibiotics, making them unaffordable for the domestic health insurance system. Antibiotics introduced in Republic of Korea over the past decade include tigecycline 
(2007), doripenem (2010), zabofloxacin (2015), and daptomycin (2021), which have been approved of the Ministry of Food and Drug Safety (MFDS). Tedizolid (2015) was approved but not sold in Republic of Korea, and ceftolozane/ tazobactam (2017) was approved by the MFDS as non-reimbursable [15]. Here we introduce novel antibiotics for MDR bacteria that have received regulatory approval by both the U.S. Food and Drug Administration (FDA) and the European Medicines Agency (EMA) from 2009 to October 2021. We recommend that these antibiotics be adopted in Republic of Korea. The scope of the review did not encompass new drugs targeting tuberculosis, Clostridioides difficile, fungi, or viruses.

\section{AGENTS TARGETING GRAM-POSITIVE BAC- TERIA}

Table 1 lists novel antibiotics active against Gram-positive bacteria that were approved by the FDA and EMA from 2009 to October 2021.

\section{Telavancin}

Telavancin, oritavancin, and dalbavancin are next-generation lipoglycopeptide antibiotics. They are vancomycin derivatives that contain both lipophilic and hydrophobic side chains. This structural modification enhances their antibacterial activity compared to vancomycin [16].

Telavancin is effective for the treatment of Gram-positive bacterial infections, especially MRSA [17]. Although vancomycin and telavancin have similar activities, telavancin has a longer half-life and need be administered only once a day, and it has better tissue permeability than vancomycin [18]. In a clinical study of complicated skin and skin structure infections, telavancin was comparably effective to standard of care, such as vancomycin $[19,20]$. The rate of microbiological eradication in patients with MRSA infections was $84 \%$ in the telavancin group and $74 \%$ in the standard of care group. Telavancin exhibited noninferiority to vancomycin in two phase 3 clinical trials involving patients with nosocomial pneumonia caused by Gram-positive bacteria [21]. However, when telavancin was used in patients with impaired renal function (creatinine clearance rate $\leq 50 \mathrm{~mL} / \mathrm{min}$ ), the mortality rate was higher than that of vancomycin. Therefore, clinicians should consider using telavancin instead of vancomycin for the treatment of MRSA in cases with a high minimum inhibitory concentration of vancomycin. The risks and benefits to patients should be weighed when making treatment decisions.

Enterococci harboring the vanA gene can be resistant to telavancin; however, enterococci with the vanB gene are susceptible. Therefore, telavancin can be used to treat infections caused by VRE strains that have the vanB gene [17].

\section{Oritavancin}

Oritavancin is a novel lipoglycopeptide antibiotic active against MRSA, VRSA, and VRE [16]. Oritavancin has good antimicrobial activity against VRE. The minimum inhibitory concentration of oritavancin for $90 \%$ of strains was 0.12 $\mu \mathrm{g} / \mathrm{mL}$ for VRE that harbor vanA, and $\leq 0.008 \mu \mathrm{g} / \mathrm{mL}$ for VRE that harbor the vanB gene [16].

Oritavancin was approved by the FDA for the treatment of acute bacterial skin and skin structure infections (ABSSSIs). Oritavancin has a long half-life (393 hours), and a single dose of 1,200 mg is recommended for ABSSSIs. A randomized trial of oritavancin revealed its noninferiority to vancomycin for the treatment of ABSSSIs [22]. The investigator-assessed clinical cure rate was $79.6 \%$ in the oritavancin group and $80.0 \%$ in the vancomycin group.

\section{Dalbavancin}

Dalbavancin was developed as an alternative to vancomycin; its higher antimicrobial activity and prolonged half-life compared with vancomycin enable administration of dalbavancin as a single dose treatment regimen for ABSSSIs [23]. A randomized clinical trial demonstrated its noninferiority to vancomycin followed by oral linezolid for ABSSSIs (response rate, $79.7 \%$ vs. $79.8 \% ; 95 \%$ confidence interval $[\mathrm{Cl}]$ of the weighted difference, -4.5 to 4.2 ) [24]. Additionally, dalbavancin was approved by the FDA for the treatment for ABSSSIs in pediatric patients from birth [25]. Dalbavancin reportedly exhibits satisfactory activity against MRSA and even biofilms of $S$. aureus. It also has activity against VRE with the vanB gene but not strains with the vanA gene [26].

\section{Ceftaroline}

As for other $\beta$-lactams, ceftaroline binds to penicillin-binding proteins to inhibit cell-wall synthesis. Ceftaroline exhibits a high affinity for penicillin-binding protein $2 \mathrm{a}$, which is related to methicillin resistance [27]. Ceftaroline can be used for the treatment of infections caused by MRSA, vancomycin intermediate-resistant $S$. aureus (VISA), and VRSA. It has 
Table 1. Characteristics of new Gram-positive antibacterial drugs that received regulatory approval by the FDA and EMA from 2009 to October 2021

\begin{tabular}{|c|c|c|c|c|c|c|c|c|}
\hline Name & Class & $\begin{array}{c}\text { Approval } \\
\text { status (year } \\
\text { approved) }\end{array}$ & $\begin{array}{l}\text { Cost }(2021 \\
\text { US\$) }\end{array}$ & Indications & $\begin{array}{c}\text { Dose and } \\
\text { dosing interval }\end{array}$ & $\begin{array}{l}\text { Activity } \\
\text { against } \\
\text { MRSA }\end{array}$ & $\begin{array}{c}\text { Activity } \\
\text { against } \\
\text { VISA/VRSA }\end{array}$ & $\begin{array}{c}\text { Activity against } \\
\text { VRE }\end{array}$ \\
\hline Telavancin & Glycopeptide & $\begin{array}{l}\text { FDA (2009), } \\
\text { EMA (2009) }\end{array}$ & $\begin{array}{l}587.26 \\
\text { (per } 750 \mathrm{mg} \text { ) }\end{array}$ & $\begin{array}{l}\text { cSSSI } \\
\text { HABPI } \\
\text { VABP }\end{array}$ & $\begin{array}{l}10 \mathrm{mg} / \mathrm{kg} \text { by IV } \\
\text { infusion over } \\
60 \mathrm{~min} \text { every } \\
24 \mathrm{hr}\end{array}$ & Active & $\begin{array}{l}\text { Active only } \\
\text { against } \\
\text { VISA }\end{array}$ & $\begin{array}{l}\text { Active against } \\
\text { VRE with the } \\
\text { vanB gene }\end{array}$ \\
\hline Oritavancin & Glycopeptide & $\begin{array}{l}\text { FDA (2014), } \\
\text { EMA (2015) }\end{array}$ & $\begin{array}{l}1,073.96 \\
\text { (per } 400 \text { mg) }\end{array}$ & ABSSSIS & $\begin{array}{l}\text { 1,200 mg by IV } \\
\text { infusion over } 3 \\
\text { hr as a single } \\
\text { dose }\end{array}$ & Active & Active & Active \\
\hline Dalbavancin & Glycopeptide & $\begin{array}{l}\text { FDA (2014), } \\
\text { EMA (2015) }\end{array}$ & $\begin{array}{l}\text { 1,709.30 } \\
\text { (per } 500 \text { mg) }\end{array}$ & ABSSSIS & $\begin{array}{l}\text { 1,500 mg by IV } \\
\text { infusion over } \\
30 \text { min as a } \\
\text { single dose }\end{array}$ & Active & Active & $\begin{array}{l}\text { Active against } \\
\text { VRE with the } \\
\text { vanB gene }\end{array}$ \\
\hline Ceftaroline & Cephalosporin & $\begin{array}{l}\text { FDA (2010), } \\
\text { EMA (2010) }\end{array}$ & $\begin{array}{l}222.08 \\
\text { (per } 600 \mathrm{mg})\end{array}$ & $\begin{array}{l}\text { ABSSSIS } \\
\text { CABP }\end{array}$ & $\begin{array}{l}600 \text { mg every } \\
12 \text { hr by } \\
\text { IV infusion } \\
\text { administered } \\
\text { over } 60 \text { min }\end{array}$ & Active & Active & $\begin{array}{l}\text { Active against } \\
\text { VR Enterococ- } \\
\text { cus faecalis }\end{array}$ \\
\hline Lefamulin & Pleuromutilin & $\begin{array}{l}\text { FDA (2019), } \\
\text { EMA (2020) }\end{array}$ & $\begin{array}{l}\text { IV solution: } \\
7.24 \\
\text { (per } 150 \mathrm{mg} \text { ) } \\
\text { Oral tablet: } \\
144.50 \\
\text { (per } 600 \mathrm{mg} \text { ) }\end{array}$ & CABP & $\begin{array}{l}150 \text { mg every } \\
12 \text { hr by IV } \\
\text { infusion over } \\
60 \text { min or } \\
600 \text { mg orally } \\
\text { every } 12 \text { hr }\end{array}$ & Active & Active & $\begin{array}{l}\text { Active against } \\
\text { VR Enterococ- } \\
\text { cus faecium }\end{array}$ \\
\hline Delafloxacin & Fluroquinolone & $\begin{array}{l}\text { FDA (2017), } \\
\text { EMA (2019) }\end{array}$ & $\begin{array}{l}\text { IV solution: } \\
144.81 \\
\text { (per } 300 \mathrm{mg} \text { ) } \\
\text { Oral tablet: } \\
\text { 74.47-81.28 } \\
\text { (per } 450 \mathrm{mg} \text { ) }\end{array}$ & ABSSSIS & $\begin{array}{l}300 \text { mg by IV } \\
\text { infusion over } \\
60 \text { min every } \\
12 \mathrm{hr} \text {, or } 450 \\
\text { mg orally } \\
\text { every } 12 \mathrm{hr}\end{array}$ & Active & Various & $\begin{array}{l}\text { Active against } \\
\text { VR Enterococ- } \\
\text { cus faecalis }\end{array}$ \\
\hline
\end{tabular}

FDA, U.S. Food and Drug Administration; EMA, European Medicines Agency; MRSA, methicillin-resistant Staphylococcus aureus; VISA, vancomycin intermediate-resistant Staphylococcus aureus; VRSA, vancomycin-resistant Staphylococcus aureus; VRE, vancomycin-resistant Enterococcus; cSSSI, complicated skin and skin structure infection; HABP, hospital-acquired bacterial pneumonia; VABP, ventilator-associated bacterial pneumonia; IV, intravenous; ABSSSI, acute bacterial skin and skin structure infection; CABP, community-acquired bacterial pneumonia; VR, vancomycin-resistant.

${ }^{\text {a }}$ Referenced in the price guide on Drugs.com.

in vitro activity against vancomycin-resistant Enterococcus faecalis but not against $E$. faecium. In addition, ceftaroline has activity against clinically relevant Gram-negative bacteria, including Haemophilus influenzae, Moraxella catarrhalis, non-extended-spectrum $\beta$-lactamase (ESBL)-producing Escherichia coli, and Klebsiella pneumoniae but not against
$P$. aeruginosa or Acinetobacter species or $\beta$-lactamase-producing, AmpC-derepressed Enterobacterales [27,28].

In phase 3 studies, the clinical cure rate of ceftaroline was noninferior to that of vancomycin plus aztreonam $(91.6 \%-$ $92.2 \%$ vs. 92.1\%-92.7\%) for ABSSSIs [29-32]. Phase 3 trials involving patients with community-acquired bacterial 
pneumonia (CABP) indicated that ceftaroline was noninferior to ceftriaxone [33]. The clinical cure rate for ceftaroline and ceftriaxone was $84.3 \%$ and $77.7 \%$, respectively.

\section{Lefamulin}

Lefamulin was the first systemic pleuromutilin antibiotic agent approved by the FDA and EMA, and is available as oral and intravenous (IV) formulations [34]. It has broad-spectrum activity against Gram-positive, Gram-negative, and anaerobic pathogens, as well as atypical bacteria [35]. Lefamulin has bactericidal activity against MRSA and vancomycin-resistant $E$. faecium but not $E$. faecalis $[35,36]$. $H$. influenzae and $M$. catarrhalis are reportedly susceptible, and lefamulin has limited activity against $P$. aeruginosa, $A$. baumannii, and Enterobacterales [34,35].

For the treatment of CABP, lefamulin (oral and IV formulations) was noninferior to moxifloxacin and well tolerated $[37,38]$. Additionally, a phase 2 trial demonstrated the efficacy of lefamulin against ABSSSIs [39].

\section{Delafloxacin}

Delafloxacin is a fluoroquinolone with increased activity in acidic environments, such as those encountered with ABSSSIs. It is active against most Gram-positive pathogens, including MRSA and E. faecalis [40]. When used to treat MRSA biofilm-mediated infections, delafloxacin was more potent than daptomycin [41]. However, delafloxacin was active against only $4.6 \%$ of $E$. faecium strains [42]. In addition, $40 \%$ of VISA isolates were susceptible to delafloxacin; however, only $7 \%$ of VRSA isolates were susceptible [43]. Regarding Gram-negative bacteria, most fluoroquinolone-resistant Enterobacterales in one study had lower susceptibility to delafloxacin than susceptible Enterobacterales [44]. Only 54\% of $P$. aeruginosa isolates were susceptible to delafloxacin [42].

Delafloxacin is reportedly noninferior to vancomycin plus aztreonam for the treatment of ABSSSIs [45,46], and is safer and more efficacious than tigecycline [47]. Compared with moxifloxacin, delafloxacin was effective against CABP [48]. In seven hospitals in New York City, 22\% of MRSA isolates were resistant to delafloxacin [49]. Therefore, it is important to determine the delafloxacin susceptibility of MRSA strains isolated in Republic of Korea.

\section{AGENTS TARGETING GRAM-NEGATIVE BACTERIA}

Table 2 lists the novel antibiotics active against MDR Gram-negative bacteria approved by the FDA and EMA from 2009 to October 2021. Their activities against MDR Gram-negative bacteria are described in Table 3.

\section{Cefiderocol}

Cefiderocol was the first novel siderophore cephalosporin approved for MDR Gram-negative pathogens. It has a unique iron transporter-based mechanism that uses the siderophore-iron complex pathway of Gram-negative bacteria to enable penetration of the bacterial outer membrane [50]. Cefiderocol is active against all Ambler classes of $\beta$-lactamases (e.g., K. pneumoniae carbapenemase [KPC], Verona integron-encoded metallo- $\beta$-lactamase, oxacillinase [OXA]-48-like carbapenemases), and New Delhi metallo- $\beta$-lactamase (NDM) [51,52]. It also has considerable activity against MRAB, MRPA, and Stenotrophomonas maltophilia [52-56].

In a phase 2 study, cefiderocol was noninferior to imipenem-cilastatin for patients with complicated urinary tract infections (cUTIs) caused by Gram-negative bacteria [57]. In a phase 3 study of treatments for nosocomial pneumonia caused by Gram-negative pathogens, cefiderocol was noninferior to high-dose, extended-infusion meropenem [58]. In another phase 3 study, its efficacy and safety for the treatment for serious infections caused by carbapenem-resistant Gram-negative bacteria were confirmed in comparison to the best-available therapy. However, there were more deaths in the cefiderocol group than in the best available therapy group (34\% vs. $18 \%$ ) by the end of the study period, particularly in patients with Acinetobacter spp. infections [59]. Resistance to cefiderocol has been reported $[60,61]$.

\section{Ceftazidime-avibactam}

Ceftazidime-avibactam is a combination of a third-generation cephalosporin and a newly developed non- $\beta$-lactam $\beta$-lactamase inhibitor, prepared at a fixed ceftazidime: avibactam ratio of 4:1 [62]. It has high activity against ESBL-, AmpC-, KPC-, and OXA-48-producing Enterobacterales. Moreover, MRPA is susceptible to ceftazidime-avibactam [52]. However, the drug is not active against most $A$ cinetobacter species or metallo- $\beta$-lactamase-producing isolates [63]. 
Table 2. Characteristics of new Gram-negative antibacterial drugs that received regulatory approval by the FDA and EMA from 2009 to October 2021

\begin{tabular}{|c|c|c|c|c|c|}
\hline Name & Class & $\begin{array}{l}\text { Approval } \\
\text { status (year } \\
\text { approved) }\end{array}$ & $\begin{array}{l}\text { Cost } \\
(2021 \text { US } \$)^{a}\end{array}$ & Indications & Dose and dosing interval \\
\hline Cefiderocol & $\begin{array}{l}\text { Cephalosporin } \\
\text { siderophore }\end{array}$ & $\begin{array}{l}\operatorname{FDA}(2019) \\
\operatorname{EMA}(2020)\end{array}$ & $\begin{array}{l}199.05 \\
(\text { per } 1 \mathrm{~g})\end{array}$ & $\begin{array}{l}\text { CUTI, HABPI } \\
\text { VABP }\end{array}$ & $\begin{array}{l}2 \mathrm{~g} \text { every } 8 \mathrm{hr} \text { by IV infusion } \\
\text { over } 3 \mathrm{hr}\end{array}$ \\
\hline $\begin{array}{l}\text { Ceftazidime- } \\
\text { avibactam }\end{array}$ & $\begin{array}{l}\beta \text {-Lactam + } \\
\text { diazabicyclooctane BLI }\end{array}$ & $\begin{array}{l}\text { FDA (2015), } \\
\text { EMA (2016) }\end{array}$ & $\begin{array}{l}375.55 \\
\text { (per } 2.5 \mathrm{~g})\end{array}$ & $\begin{array}{l}\text { HABP/VABP, } \\
\text { ClAI, CUTI }\end{array}$ & $\begin{array}{l}\text { Ceftazidime: } 2 \mathrm{~g} \text { and avibactam: } \\
0.5 \mathrm{~g} \text { by IV infusion over } 2 \mathrm{hr} \text { every } 8 \mathrm{hr}\end{array}$ \\
\hline $\begin{array}{l}\text { Imipenem-cilasta- } \\
\text { tin-relebactam }\end{array}$ & $\begin{array}{l}\text { } \beta \text {-Lactam + renal } \\
\text { dehydropeptidase } \\
\text { inhibitor + diazabicy- } \\
\text { clooctane BLI }\end{array}$ & $\begin{array}{l}\text { FDA (2019), } \\
\operatorname{EMA~}(2020)\end{array}$ & $\begin{array}{l}288.03 \\
\quad(\text { per } 1.25 \mathrm{~g})\end{array}$ & $\begin{array}{l}\text { CIAI, cUTI, } \\
\text { HABP/VABP }\end{array}$ & $\begin{array}{l}\text { Imipenem: } 500 \text { mg, cilastatin: } \\
500 \text { mg, and relebactam: } 250 \text { mg by } \\
\text { IV infusion over } 30 \text { min every } 6 \text { hr }\end{array}$ \\
\hline $\begin{array}{l}\text { Meropenem- } \\
\text { vaborbactam }\end{array}$ & $\begin{array}{l}\beta \text {-Lactam + } \\
\text { boronate BLI }\end{array}$ & $\begin{array}{l}\text { FDA (2017), } \\
\text { EMA (2018) }\end{array}$ & $\begin{array}{l}196.99 \\
(\text { per } 2 \text { g) }\end{array}$ & CUTI & $\begin{array}{l}\text { Meropenem: } 2 \mathrm{~g} \text { and vaborbactam: } 2 \mathrm{~g} \\
\text { every } 8 \mathrm{hr} \text { by IV infusion over } 3 \mathrm{hr}\end{array}$ \\
\hline Eravacycline & Tetracycline & $\begin{array}{l}\text { FDA (2018), } \\
\text { EMA (2018) }\end{array}$ & $\begin{array}{l}51.95 \\
\text { (per } 50 \mathrm{mg})\end{array}$ & $\mathrm{ClAl}$ & $\begin{array}{l}1 \mathrm{mg} / \mathrm{kg} \text { by IV infusion over } \\
\text { approximately } 60 \text { min every } 12 \mathrm{hr}\end{array}$ \\
\hline
\end{tabular}

FDA, U.S. Food and Drug Administration; EMA, European Medicines Agency; cUTI, complicated urinary tract infection; HABP, hospital-acquired bacterial pneumonia; VABP, ventilator-associated bacterial pneumonia; IV, intravenous; BLI, $\beta$-lactamase inhibitor; CIAI, complicated intraabdominal infection.

${ }^{a}$ Referenced in the price guide on Drugs.com.

Table 3. Activities of novel antibiotics against Gram-negative bacteria

\begin{tabular}{|c|c|c|c|c|c|c|}
\hline \multirow[b]{2}{*}{ Novel antibiotics } & \multicolumn{4}{|c|}{ Enterobacterales } & \multirow[b]{2}{*}{$\begin{array}{l}\text { Carbapenem- } \\
\text { resistant Pseudo- } \\
\text { monas aeruginosa }\end{array}$} & \multirow[b]{2}{*}{$\begin{array}{l}\text { Carbapen- } \\
\text { em-resistant } \\
\text { Acinetobacter } \\
\text { baumannii }\end{array}$} \\
\hline & $\begin{array}{l}\text { Extended- } \\
\text { spectrum } \\
\beta \text {-lactamase }\end{array}$ & $\begin{array}{c}\text { Class } \\
\text { A carbapenemase } \\
\text { (KPC) }\end{array}$ & $\begin{array}{l}\text { Class } \\
\text { B carbap- } \\
\text { enemase } \\
\text { (NDM) }\end{array}$ & $\begin{array}{c}\text { Class } \\
\text { D carbapene- } \\
\text { mase (OXA-48- } \\
\text { like) }\end{array}$ & & \\
\hline Cefiderocol & Yes & Yes & Yes & Yes & Yes & Yes \\
\hline $\begin{array}{l}\text { Ceftazidime- } \\
\text { avibactam }\end{array}$ & Yes & Yes & No & Yes & Yes & No \\
\hline $\begin{array}{l}\text { Imipenem- } \\
\text { cilastatin-relebactam }\end{array}$ & Yes & Yes & No & No & Yes & No \\
\hline $\begin{array}{l}\text { Meropenem- } \\
\text { vaborbactam }\end{array}$ & Yes & Yes & No & No & No & No \\
\hline Eravacycline & Yes & Yes & Yes & Yes & No & Yes \\
\hline
\end{tabular}

KPC, Klebsiella pneumoniae carbapenemase; NDM, New Delhi metallo- $\beta$-lactamase; OXA, oxacillinase.

Ceftazidime-avibactam plus metronidazole exhibited noninferiority to meropenem in a phase 3 study of patients with complicated intraabdominal infections [64]. Ceftazidime-avibactam was noninferior to doripenem for the treatment of cUTIs [65]. The microbiological eradication rate was $77.4 \%$ in the ceftazidime-avibactam group and $71.0 \%$ in the doripenem group (95\% Cl for the difference, 0.33\% to $12.36 \%)$. Ceftazidime-avibactam exhibited high activity against KPC-producing CRE compared to colistin in a prospective observational study [66]. It is also reportedly noninferior to meropenem for the treatment of nosocomial pneumonia and ventilator-associated pneumonia [67]. 
Because of the limited availability of therapeutic agents, ceftazidime-avibactam has emerged as an alternative to colistin for the treatment of infections caused by CRE $[68,69]$. Ceftazidime-avibactam resistance has been reported in carbapenem-resistant $K$. pneumoniae isolates [70-72]. Therefore, the application of and rationale for the use of ceftazidime-avibactam require careful consideration [69,73].

\section{Imipenem-cilastatin-relebactam}

Imipenem-cilastatin-relebactam is a combination of a pre-existing carbapenem, imipenem-cilastatin, and a new $\beta$-lactamase inhibitor, relebactam. It has activity against KPC-producing, but not NDM-producing, Enterobacterales. It is also active against MRPA [52]. However, imipenem-cilastatin-relebactam has limited activity against $A$. baumannii isolates that harbor class $D \beta$-lactamases [74].

Imipenem-cilastatin-relebactam reportedly exhibits noninferiority to piperacillin/tazobactam in patients with nosocomial pneumonia and ventilator-associated pneumonia, including those at high risk [75,76]. In a phase 2 study involving patients with CUTIs, imipenem-cilastatin-relebactam (125 mg relebactam) was noninferior to imipenem-cilastatin (clinical response rate $97.1 \%$ vs. $98.8 \%$ ) [77]. Imipenem-cilastatin-relebactam also yields favorable clinical responses in patients with imipenem-non-susceptible bacterial infections and has a lower all-cause mortality rate than colistin plus imipenem-cilastatin [78].

\section{Meropenem-vaborbactam}

Meropenem-vaborbactam is the first approved combination of a carbapenem and a $\beta$-lactamase inhibitor. Meropenem-vaborbactam is effective against numerous Gram-negative bacteria, including KPC-producing CRE [52]. However, vaborbactam has no activity against NDM and OXA-48-like producers and does not improve the activity of meropenem against non-fermenting Gram-negative bacteria, such as carbapenem-resistant $P$. aeruginosa or Acinetobacter spp. [79]. In patients with cUTIs, meropenem-vaborbactam showed an overall treatment success rate of $98.4 \%$ in a randomized clinical trial and was noninferior to piperacillin-tazobactam (overall success rate, $94.0 \%$; $95 \% \mathrm{Cl}$ for the difference, $0.7 \%$ to $9.1 \%$ ) [80]. In a study of CRE infections, meropenem-vaborbactam had a lower mortality rate, a higher clinical cure rate, and less nephrotoxicity than the best available therapy [81].

\section{Eravacycline}

Eravacycline is a novel fluorocycline antibiotic with a similar structure to tigecycline; however, eravacycline is more potent against Gram-positive, Gran-negative, and anaerobic pathogens than tigecycline. Specifically, it is active against MRSA, VRE, ESBL-producing Enterobacterales, CRE, and MRAB. However, as for tigecycline, eravacycline has no activity against $P$. aeruginosa, Morganella spp., Proteus spp., or Providencia spp. [52,82].

In a phase 3 study of patients with complicated intraabdominal infections, eravacycline exhibited noninferiority to meropenem (clinical cure rate, $90.8 \%$ vs. $91.2 \% ; 95 \% \mathrm{Cl}$, $-6.3 \%$ to $5.3 \%$ ) [83]. A randomized clinical trial compared eravacycline and levofloxacin for the treatment of cUTIs; however, to our knowledge, the results have not been published [84]. Based on available data, eravacycline is a potential alternative to conventional antibiotics for the treatment of infections caused by MDR bacteria [69]. However, it should be used with caution to avoid the emergence of resistance [85].

\section{CONCLUSIONS}

Infections with MDR bacteria have high mortality rates $[86,87]$. Currently, few antibiotics are available in Republic of Korea. In addition to those covered in this review, other antibiotics—such as iclaprim, ceftobiprole medocaril, aztreonam-avibactam, and darobactin-await regulatory approval by the FDA and EMA. To prevent the emergence of antibiotic resistance, new antibiotics should not be used empirically; they should be based on the susceptibility of and resistance genes harbored by the causative bacteria. Rapid identification of pathogens and resistance genes is essential for effective antibiotic treatment [88]. In addition, antimicrobial stewardship programs should be implemented in hospitals $[89,90]$. The Republic of Korean national action plan on antimicrobial resistance was established in 2016. Collaborative efforts by the government, academia, and pharmaceutical companies would expedite the regulatory approval of novel antibiotics in Republic of Korea, enhancing patient care and treatment.

\section{Conflict of interest}

No potential conflict of interest relevant to this article was reported. 


\section{REFERENCES}

1. Kim B, Hwang H, Kim J, Lee MJ, Pai H. Ten-year trends in antibiotic usage at a tertiary care hospital in Korea, 2004 to 2013. Korean J Intern Med 2020;35:703-713.

2. Flores-Paredes W, Luque N, Albornoz R, et al. Evolution of antimicrobial resistance levels of ESKAPE microorganisms in a Peruvian IV-level hospital. Infect Chemother 2021;53:449462.

3. Khuntayaporn P, Yamprayoonswat W, Yasawong M, Chomnawang MT. Dissemination of carbapenem-resistance among multidrug resistant Pseudomonas aeruginosa carrying metallo-beta-lactamase genes, including the novel bla|MP-65 gene in Thailand. Infect Chemother 2019;51:107-118.

4. Butler MS, Paterson DL. Antibiotics in the clinical pipeline in October 2019. J Antibiot (Tokyo) 2020;73:329-364.

5. Duval RE, Grare M, Demore B. Fight against antimicrobial resistance: we always need new antibacterials but for right bacteria. Molecules 2019;24:3152.

6. Lee CS. Are community-based hospitals safe from carbapenem-resistant Enterobacteriaceae in Korea? Infect Chemother 2016;48:246-248.

7. Kim HS, Kim DH, Yoon HJ, Lee WJ, Woo SH, Choi SP. Factors associated with vancomycin-resistant enterococcus colonization in patients transferred to emergency departments in Korea. J Korean Med Sci 2018;33:e295.

8. Choi YK, Byeon EJ, Park JJ, Lee J, Seo YB. Antibiotic resistance patterns of Enterobacteriaceae isolated from patients with healthcare-associated infections. Infect Chemother 2021;53:355-363.

9. Hong J, Jang OJ, Bak MH, et al. Management of carbapenem-resistant Acinetobacter baumannii epidemic in an intensive care unit using multifaceted intervention strategy. Korean J Intern Med 2018;33:1000-1007.

10. Jung SM, Kim YJ, Ryoo SM, et al. Cancer patients with neutropenic septic shock: etiology and antimicrobial resistance. Korean J Intern Med 2020;35:979-987.

11. Sobhanipoor MH, Ahmadrajabi R, Nave HH, Saffari F. Reduced susceptibility to biocides among enterococci from clinical and non-clinical sources. Infect Chemother 2021;53:696-704.

12. Kim YA, Park YS. Epidemiology and treatment of antimicrobialresistant Gram-negative bacteria in Korea. Korean J Intern Med 2018;33:247-255.

13. Liu C, Yoon EJ, Kim D, et al. Antimicrobial resistance in South Korea: a report from the Korean global antimicrobial resistance surveillance system (Kor-GLASS) for 2017. J Infect
Chemother 2019;25:845-859.

14. Park JW, Kwak SH, Jung J, et al. The rate of acquisition of carbapenemase-producing Enterobacteriaceae among close contact patients depending on carbapenemase enzymes. Infect Chemother 2020;52:39-47.

15. Ministry of Food and Drug Safety. 2020 Drug approval report [Internet]. Cheongju (KR): Ministry of Food and Drug Safety, 2021 [cited 2022 Jan 31]. Available from: https://www.mfds. go.kr/eng/brd/m_19/view. do ?seq=70436\&srchFr=\&srchTo $=\&$ srchWord $=\&$ srchTp $=\& i t m \_s e q \_1=0 \& i t m \_s e q \_2=0 \&$ multi_itm_seq=0\&company_cd=\&company_nm=\&page $=1$.

16. Saravolatz LD, Stein GE. Oritavancin: a long-half-life lipoglycopeptide. Clin Infect Dis 2015;61:627-632.

17. Saravolatz LD, Stein GE, Johnson LB. Telavancin: a novel lipoglycopeptide. Clin Infect Dis 2009;49:1908-1914.

18. Das B, Sarkar C, Das D, Gupta A, Kalra A, Sahni S. Telavancin: a novel semisynthetic lipoglycopeptide agent to counter the challenge of resistant Gram-positive pathogens. Ther Adv Infect Dis 2017;4:49-73.

19. Stryjewski ME, O'Riordan WD, Lau WK, et al. Telavancin versus standard therapy for treatment of complicated skin and soft-tissue infections due to Gram-positive bacteria. Clin Infect Dis 2005;40:1601-1607.

20. Choo EJ. Antimicrobial therapy for methicillin-resistant Staphylococcus aureus. J Korean Med Assoc 2018;61:207-213.

21. Sandrock CE, Shorr AF. The role of telavancin in hospital-acquired pneumonia and ventilator-associated pneumonia. Clin Infect Dis 2015;61 Suppl 2:S79-S86.

22. Corey GR, Kabler H, Mehra P, et al. Single-dose oritavancin in the treatment of acute bacterial skin infections. N Engl J Med 2014;370:2180-2190.

23. Dunne MW, Puttagunta S, Giordano P, Krievins D, Zelasky M, Baldassarre J. A randomized clinical trial of single-dose versus weekly dalbavancin for treatment of acute bacterial skin and skin structure infection. Clin Infect Dis 2016;62:545-551.

24. Boucher HW, Wilcox M, Talbot GH, Puttagunta S, Das AF, Dunne MW. Once-weekly dalbavancin versus daily conventional therapy for skin infection. N Engl J Med 2014;370:2169-2179.

25. Gonzalez D, Bradley JS, Blumer J, et al. Dalbavancin pharmacokinetics and safety in children 3 months to 11 years of age. Pediatr Infect Dis J 2017;36:645-653.

26. Soriano A, Rossolini GM, Pea F. The role of dalbavancin in the treatment of acute bacterial skin and skin structure infections (ABSSSIs). Expert Rev Anti Infect Ther 2020;18:415-422.

27. Saravolatz LD, Stein GE, Johnson LB. Ceftaroline: a novel 
cephalosporin with activity against methicillin-resistant Staphylococcus aureus. Clin Infect Dis 2011;52:1156-1163.

28. Scott $\sqcup$. Ceftaroline fosamil: a review in complicated skin and soft tissue infections and community-acquired pneumonia. Drugs 2016;76:1659-1674.

29. Corey GR, Wilcox M, Talbot GH, et al. Integrated analysis of CANVAS 1 and 2: phase 3, multicenter, randomized, double-blind studies to evaluate the safety and efficacy of ceftaroline versus vancomycin plus aztreonam in complicated skin and skin-structure infection. Clin Infect Dis 2010;51:641-650.

30. Corey GR, Wilcox MH, Talbot GH, et al. CANVAS 1: the first phase III, randomized, double-blind study evaluating Ceftaroline fosamil for the treatment of patients with complicated skin and skin structure infections. J Antimicrob Chemother 2010;65 Suppl 4:iv41-iv51.

31. Corrado ML. Integrated safety summary of CANVAS 1 and 2 trials: phase III, randomized, double-blind studies evaluating ceftaroline fosamil for the treatment of patients with complicated skin and skin structure infections. J Antimicrob Chemother 2010;65 Suppl 4:iv67-iv71.

32. Wilcox MH, Corey GR, Talbot GH, et al. CANVAS 2: the second phase III, randomized, double-blind study evaluating Ceftaroline fosamil for the treatment of patients with complicated skin and skin structure infections. J Antimicrob Chemother 2010;65 Suppl 4:iv53-iv65.

33. File TM Jr, Low DE, Eckburg PB, et al. Integrated analysis of FOCUS 1 and FOCUS 2: randomized, doubled-blinded, multicenter phase 3 trials of the efficacy and safety of Ceftaroline fosamil versus ceftriaxone in patients with community-acquired pneumonia. Clin Infect Dis 2010;51:1395-1405.

34. Zhanel GG, Deng C, Zelenitsky S, et al. Lefamulin: a novel oral and intravenous pleuromutilin for the treatment of community-acquired bacterial pneumonia. Drugs 2021;81:233-256.

35. Watkins RR, File TM. Lefamulin: a novel semisynthetic pleuromutilin antibiotic for community-acquired bacterial pneumonia. Clin Infect Dis 2020;71:2757-2762.

36. Paukner S, Gelone SP, Arends S, Flamm RK, Sader HS. Antibacterial activity of lefamulin against pathogens most commonly causing community-acquired bacterial pneumonia: SENTRY antimicrobial surveillance program (2015-2016). Antimicrob Agents Chemother 2019;63:e02161-18.

37. File TM, Goldberg L, Das A, et al. Efficacy and safety of intravenous-to-oral lefamulin, a pleuromutilin antibiotic, for the treatment of community-acquired bacterial pneumonia: the phase III lefamulin evaluation against pneumonia (LEAP 1) trial. Clin Infect Dis 2019;69:1856-1867.
38. Alexander E, Goldberg L, Das AF, et al. Oral lefamulin vs moxifloxacin for early clinical response among adults with community-acquired bacterial pneumonia: the LEAP 2 randomized clinical trial. JAMA 2019;322:1661-1671.

39. Rubino CM, Xue B, Bhavnani SM, et al. Population pharmacokinetic analyses for BC-3781 using phase 2 data from patients with acute bacterial skin and skin structure infections. Antimicrob Agents Chemother 2015;59:282-288.

40. Scott $\sqcup$. Delafloxacin: a review in acute bacterial skin and skin structure infections. Drugs 2020;80:1247-1258.

41. Siala W, Mingeot-Leclercq MP, Tulkens PM, Hallin M, Denis O, Van Bambeke F. Comparison of the antibiotic activities of daptomycin, vancomycin, and the investigational fluoroquinolone delafloxacin against biofilms from Staphylococcus aureus clinical isolates. Antimicrob Agents Chemother 2014;58:63856397.

42. Saravolatz LD, Stein GE. Delafloxacin: a new anti-methicillin-resistant Staphylococcus aureus fluoroquinolone. Clin Infect Dis 2019;68:1058-1062.

43. Saravolatz LD, Pawlak JM, Wegner C. Delafloxacin activity against Staphylococcus aureus with reduced susceptibility or resistance to methicillin, vancomycin, daptomycin or linezolid. J Antimicrob Chemother 2020;75:2605-2608.

44. Pfaller MA, Sader HS, Rhomberg PR, Flamm RK. In vitro activity of delafloxacin against contemporary bacterial pathogens from the United States and Europe, 2014. Antimicrob Agents Chemother 2017;61:e02609-16.

45. O'Riordan W, McManus A, Teras J, et al. A comparison of the efficacy and safety of intravenous followed by oral delafloxacin with vancomycin plus aztreonam for the treatment of acute bacterial skin and skin structure infections: a phase 3, multinational, double-blind, randomized study. Clin Infect Dis 2018;67:657-666.

46. Pullman J, Gardovskis J, Farley B, et al. Efficacy and safety of delafloxacin compared with vancomycin plus aztreonam for acute bacterial skin and skin structure infections: a phase 3, double-blind, randomized study. J Antimicrob Chemother 2017;72:3471-3480.

47. O'Riordan W, Mehra P, Manos P, Kingsley J, Lawrence L, Cammarata $S$. A randomized phase 2 study comparing two doses of delafloxacin with tigecycline in adults with complicated skin and skin-structure infections. Int J Infect Dis 2015;30:6773.

48. Horcajada JP, Salata RA, Alvarez-Sala R, et al. A phase 3 study to compare delafloxacin with moxifloxacin for the treatment of adults with community-acquired bacterial pneumonia (DE- 
FINE-CABP). Open Forum Infect Dis 2019;7:ofz514.

49. Iregui A, Khan Z, Malik S, Landman D, Quale J. Emergence of delafloxacin-resistant Staphylococcus aureus in Brooklyn, New York. Clin Infect Dis 2020;70:1758-1760.

50. Wu JY, Srinivas P, Pogue JM. Cefiderocol: a novel agent for the management of multidrug-resistant Gram-negative organisms. Infect Dis Ther 2020;9:17-40.

51. Syed YY. Cefiderocol: a review in serious Gram-negative bacterial infections. Drugs 2021;81:1559-1571.

52. Tamma PD, Aitken SL, Bonomo RA, Mathers AJ, van Duin D, Clancy CJ. Infectious Diseases Society of America guidance on the treatment of AmpC $\beta$-lactamase-producing Enterobacterales, carbapenem-resistant Acinetobacter baumannii, and Stenotrophomonas maltophilia infections. Clin Infect Dis 2021 Dec 5 [Epub]. https://doi.org/10.1093/cid/ciab1013.

53. Iregui A, Khan Z, Landman D, Quale J. Activity of cefiderocol against Enterobacterales, Pseudomonas aeruginosa, and Acinetobacter baumannii endemic to medical centers in New York City. Microb Drug Resist 2020;26:722-726.

54. Yamano $Y$. In vitro activity of cefiderocol against a broad range of clinically important Gram-negative bacteria. Clin Infect Dis 2019;69(Suppl 7):S544-S551.

55. Kazmierczak KM, Tsuji M, Wise MG, et al. In vitro activity of cefiderocol, a siderophore cephalosporin, against a recent collection of clinically relevant carbapenem-non-susceptible Gram-negative bacilli, including serine carbapenemase- and metallo- $\beta$-lactamase-producing isolates (SIDERO-WT-2014 Study). Int J Antimicrob Agents 2019;53:177-184.

56. Karlowsky JA, Hackel MA, Tsuji M, Yamano Y, Echols R, Sahm DF. In vitro activity of cefiderocol, a siderophore cephalosporin, against Gram-negative bacilli isolated by clinical laboratories in North America and Europe in 2015-2016: SIDERO-WT-2015. Int J Antimicrob Agents 2019;53:456-466.

57. Portsmouth $S$, van Veenhuyzen $D$, Echols $R$, et al. Cefiderocol versus imipenem-cilastatin for the treatment of complicated urinary tract infections caused by Gram-negative uropathogens: a phase 2, randomised, double-blind, non-inferiority trial. Lancet Infect Dis 2018;18:1319-1328.

58. Wunderink RG, Matsunaga $Y$, Ariyasu $M$, et al. Cefiderocol versus high-dose, extended-infusion meropenem for the treatment of Gram-negative nosocomial pneumonia (APEKSNP): a randomised, double-blind, phase 3, non-inferiority trial. Lancet Infect Dis 2021;21:213-225.

59. Bassetti M, Echols R, Matsunaga $Y$, et al. Efficacy and safety of cefiderocol or best available therapy for the treatment of serious infections caused by carbapenem-resistant Gram-neg- ative bacteria (CREDIBLE-CR): a randomised, open-label, multicentre, pathogen-focused, descriptive, phase 3 trial. Lancet Infect Dis 2021;21:226-240.

60. Streling AP, Al Obaidi MM, Lainhart WD, et al. Evolution of cefiderocol non-susceptibility in pseudomonas aeruginosa in a patient without previous exposure to the antibiotic. Clin Infect Dis 2021;73:e4472-e4474.

61. Hobson $C A$, Cointe $A$, Jacquier $H$, et al. Cross-resistance to cefiderocol and ceftazidime-avibactam in KPC $\beta$-lactamase mutants and the inoculum effect. Clin Microbiol Infect 2021;27:1172.e7-1172.e10.

62. Lee HJ, Lee DG. Carbapenem-resistant Enterobacteriaceae: recent updates and treatment strategies. J Korean Med Assoc 2018;61:281-289.

63. Shirley M. Ceftazidime-avibactam: a review in the treatment of serious Gram-negative bacterial infections. Drugs 2018;78:675-692.

64. Mazuski JE, Gasink LB, Armstrong J, et al. Efficacy and safety of ceftazidime-avibactam plus metronidazole versus meropenem in the treatment of complicated intra-abdominal infection: results from a randomized, controlled, double-blind, phase 3 program. Clin Infect Dis 2016;62:1380-1389.

65. Wagenlehner FM, Sobel JD, Newell P, et al. Ceftazidime-avibactam versus doripenem for the treatment of complicated urinary tract infections, including acute pyelonephritis: RECAPTURE, a phase 3 randomized trial program. Clin Infect Dis 2016;63:754-762.

66. van Duin D, Lok JJ, Earley $M$, et al. Colistin versus ceftazidime-avibactam in the treatment of infections due to carbapenem-resistant Enterobacteriaceae. Clin Infect Dis 2018;66:163-171.

67. Torres A, Zhong N, Pachl J, et al. Ceftazidime-avibactam versus meropenem in nosocomial pneumonia, including ventilator-associated pneumonia (REPROVE): a randomised, double-blind, phase 3 non-inferiority trial. Lancet Infect Dis 2018;18:285-295.

68. Pogue JM, Bonomo RA, Kaye KS. Ceftazidime/avibactam, meropenem/vaborbactam, or both? clinical and formulary considerations. Clin Infect Dis 2019;68:519-524.

69. Tamma PD, Aitken SL, Bonomo RA, Mathers AJ, van Duin $D$, Clancy CJ. Infectious Diseases Society of America guidance on the treatment of extended-spectrum $\beta$-lactamase producing Enterobacterales (ESBL-E), carbapenem-resistant Enterobacterales (CRE), and pseudomonas aeruginosa with difficult-to-treat resistance (DTR-P. aeruginosa). Clin Infect Dis 2021;72:1109-1116. 
70. Zhang P, Shi Q, Hu H, et al. Emergence of ceftazidime/avibactam resistance in carbapenem-resistant Klebsiella pneumoniae in China. Clin Microbiol Infect 2020;26:124.e1-124.e4.

71. Shields RK, Chen L, Cheng S, et al. Emergence of ceftazidime-avibactam resistance due to plasmid-borne bla KPC-3 $_{3}$ mutations during treatment of carbapenem-resistant klebsiella pneumoniae infections. Antimicrob Agents Chemother 2017;61:e02097-16.

72. Gottig S, Frank D, Mungo E, et al. Emergence of ceftazidime/ avibactam resistance in KPC-3-producing Klebsiella pneumoniae in vivo. J Antimicrob Chemother 2019;74:3211-3216.

73. Dietl B, Martinez LM, Calbo E, Garau J. Update on the role of ceftazidime-avibactam in the management of carbapenemase-producing Enterobacterales. Future Microbiol 2020;15:473-484.

74. Heo YA. Imipenem/cilastatin/relebactam: a review in Gram-negative bacterial infections. Drugs 2021;81:377-388.

75. Titov I, Wunderink RG, Roquilly A, et al. A randomized, double-blind, multicenter trial comparing efficacy and safety of imipenem/cilastatin/relebactam versus piperacillin/tazobactam in adults with hospital-acquired or ventilator-associated bacterial pneumonia (RESTORE-IMI 2 Study). Clin Infect Dis 2021;73:e4539-e4548.

76. Sahra S, Jahangir A, Hamadi R, Jahangir A, Glaser A. Clinical and microbiologic efficacy and safety of imipenem/cilastatin/ relebactam in complicated infections: a meta-analysis. Infect Chemother 2021;53:271-283.

77. Sims M, Mariyanovski V, McLeroth $\mathrm{P}$, et al. Prospective, randomized, double-blind, phase 2 dose-ranging study comparing efficacy and safety of imipenem/cilastatin plus relebactam with imipenem/cilastatin alone in patients with complicated urinary tract infections. J Antimicrob Chemother 2017;72:2616-2626.

78. Kaye KS, Boucher HW, Brown ML, et al. Comparison of treatment outcomes between analysis populations in the RESTORE-IMI 1 phase 3 trial of imipenem-cilastatin-relebactam versus colistin plus imipenem-cilastatin in patients with imipenem-nonsusceptible bacterial infections. Antimicrob Agents Chemother 2020;64:e02203-19.

79. Novelli A, Del Giacomo P, Rossolini GM, Tumbarello M. Meropenem/vaborbactam: a next generation $\beta$-lactam $\beta$-lactamase inhibitor combination. Expert Rev Anti Infect Ther
2020;18:643-655.

80. Kaye KS, Bhowmick T, Metallidis S, et al. Effect of meropenem-vaborbactam vs piperacillin-tazobactam on clinical cure or improvement and microbial eradication in complicated urinary tract infection: the TANGO I randomized clinical trial. JAMA 2018;319:788-799.

81. Wunderink RG, Giamarellos-Bourboulis EJ, Rahav G, et al. Effect and safety of meropenem-vaborbactam versus best-available therapy in patients with carbapenem-resistant enterobacteriaceae infections: the TANGO II randomized clinical trial. Infect Dis Ther 2018;7:439-455.

82. Zhanel GG, Cheung D, Adam H, et al. Review of eravacycline, a novel fluorocycline antibacterial agent. Drugs 2016;76:567588.

83. Solomkin JS, Gardovskis J, Lawrence K, et al. IGNITE4: results of a phase 3 , randomized, multicenter, prospective trial of eravacycline vs meropenem in the treatment of complicated intraabdominal infections. Clin Infect Dis 2019;69:921-929.

84. Tang HJ, Lai CC. The safety of eravacycline in the treatment of acute bacterial infection. Clin Infect Dis 2020;70:2750-2751.

85. Ding $Y$, Saw $W Y$, Tan $L W L$, et al. Emergence of tigecyclineand eravacycline-resistant Tet(X4)-producing Enterobacteriaceae in the gut microbiota of healthy Singaporeans. J Antimicrob Chemother 2020;75:3480-3484.

86. Hyun M, Noh Cl, Ryu SY, Kim HA. Changing trends in clinical characteristics and antibiotic susceptibility of Klebsiella pneumoniae bacteremia. Korean J Intern Med 2018;33:595-603.

87. Kim J, Kang Cl, Gwak GY, Chung DR, Peck KR, Song JH. Clinical impact of healthcare-associated acquisition in cirrhotic patients with community-onset spontaneous bacterial peritonitis. Korean J Intern Med 2020;35:215-221.

88. Mok J, Jo EJ, Eom JS, et al. Clinical efficacy of matrix-assisted laser desorption/ionization time-of-flight mass spectrometry in patients with multidrug-resistant bacteremia: a single-center study in Korea. Korean J Intern Med 2019;34:1058-1067.

89. Yoon YK, Kwon KT, Jeong SJ, et al. Guidelines on implementing antimicrobial stewardship programs in Korea. Infect Chemother 2021;53:617-659.

90. Hwang S, Kwon KT. Core elements for successful implementation of antimicrobial stewardship programs. Infect Chemother 2021;53:421-435. 